\title{
History of osteopathic medical education accreditation
}

\author{
AOA EDITORIAL DEPARTMENT
}

Since its inception, the osteopathic profession has been concerned about the quality of osteopathic medical education and the training of well-prepared, qualified physicians.

A number of osteopathic colleges were established in the last decade of the 19th century. As with many other medical colleges of their time, they shared a lack of uniformity in admission and graduation requirements. In these early years, osteopathic medical educators and leaders recognized the fact that the attainment and maintenance of high educational standards were essential to produce high-quality, competent osteopathic physicians.

In 1897, the American Association for the Advancement of Osteopathy (AAAO) was formed. Its constitution provided for a number of committees, among which was the Committee on Education.

The concept of inspection and approval of osteopathic medical colleges was introduced in 1901 when the AAAO reorganized and became the American Osteopathic Association. Its new constitution provided that the Committee on Education, together with the Executive Committee of the Associated Colleges of Osteopathy (ACO), should constitute a joint committee. This group would investigate schools applying for membership in the ACO, make annual investigations of the conditions in the schools that were already members, and prepare an annual report for the AOA Board of Trustees.

To encourage more uniform quality in educational standards among its members, the
AOA also restricted eligibility for membership to graduates of approved schools.

The first osteopathic college inspection was made in 1903, and the members of the ACO were approved.

With these actions, the AOA established itself as the body responsible for accreditation standards for the profession. Its authority and expertise were recognized by other medical organizations at the time, as well as by state legislators. Many years were to pass, however, before the AOA received full recognition on a federal level.

In 1923, the AOA Department of Education became the Bureau of Professional Education; 2 years later, the Bureau on Colleges was added. These committees later joined to become the Bureau of Professional Education and Colleges. This group was charged with the responsibility for inspection of osteopathic medical colleges.

Initially, the colleges were inspected every 2 years, and then-when the number of colleges began to grow-every 3 years. Today, the osteopathic medical colleges receive a full survey every 5 years by a survey team representing all major preclinical and clinical science disciplines. An annual report is required for each approved osteopathic medical college during the nonsurvey years.

In 1960, the education structure of the AOA was reorganized. In order to bring all facets of osteopathic medical education under one body, a new Bureau of Professional Education was created. The restructured group then became responsible for postdoctoral and continu- 
ing osteopathic medical education as well as undergraduate osteopathic education.

By developing progressively rigorous standards and methods of documentation, the AOA effectively became the watchdog of the osteopathic profession. These activities did much to convince both the public and legislators of the improved quality of osteopathic medical education and high standard of healthcare that the osteopathic profession was able to give.

In the mid-1960s, the concern for quality in accrediting procedures that had been shown by the AOA and the Bureau of Professional Education made an impact on the National Commission on Accrediting, now known as the Council on Postsecondary Accreditation (COPA), and on other national agencies concerned with education in the health professions.

COPA is the nongovernmental agency recognized by higher education institutions to approve and recognize national agencies for accreditation purposes. In 1967, COPA for the first time recognized the AOA as the official agency for accreditation of osteopathic medical education. While the association had, in effect, been acting in this capacity since its inception, this was the first time its actions were sanctioned by a higher educational authority.

Following this action, the AOA Board of Trustees, through its Department of Professional Affairs, delegated the responsibility for accreditation in a number of areas of osteopathic medical education to the Bureau of Professional Education. A subunit of this bureau, the Committee on Colleges, was charged with the responsibility of inspecting those institutions awarding the DO degree for accreditation of their educational programs.

Recognition by COPA was a first but significant step forward for educational programs within the osteopathic profession. Another even greater step quickly followed.

The federal government was expressing interest at that time in education at all levels, especially professional medical education. In 1969, the US Office of Education (USOE) examined the organizational structure and implementing documents of the Bureau. It then granted this body official status as the accrediting agency for osteopathic medical education. The USOE further recognized the Committee on Colleges as the inspecting body, and the AOA Board of Trustees as the appeals body.

The USOE (now the US Department of Education, DOE) does not grant accreditation status in perpetuity, but reviews organizations every 5 years. Those that do not meet DOE requirements are reviewed more frequently. The AOA has successfully completed each of its subsequent 5-year renewal cycles. In July 1989, the AOA once again received approval as the accrediting body for osteopathic medical education for another 5-year term.

Presently, the Bureau coordinates the activities of three committees that deal with various phases of osteopathic medical education (see Appendix I for committee membership):

- Committee on Colleges, the evaluating unit of predoctorate education;

- Committee on Postdoctoral Training, the evaluating unit of internships, residencies, preceptorships, and other postdoctorate programs;

- Committee on Continuing Medical Education, the unit that evaluates programs and recommends approval of $\mathrm{CME}$ credits. 